\title{
ADMINISTRAÇÃO ENDOVENOSA DE ANTIBIÓTICOS E RESISTÊNCIA BACTERIANA: RESPONSABILIDADE DA ENFERMAGEM*
}

\author{
INTRAVENOUS ANTIBIOTICS INFUSION AND BACTERIAL RESISTENCE: NURSING RESPONSABILITY* \\ ADMINISTRACIÓN INTRAVENOSA DE ANTIBIOTICOS Y RESISTENCIA BACTERIANA: RESPONSABILIDAD \\ DE ENFERMERÍA*
}

\section{Heloisa Helena Karnas Hoefel ${ }^{1}$, Liana Lautert ${ }^{2}$}

RESUMO: O sucesso da terapêutica com antibióticos e o desenvolvimento da resistência bacteriana dependem de diversos fatores, sendo que os relacionados ao cuidado de enfermagem são o seu preparo e a sua administração. Objetivo: realizar uma revisão da literatura sobre falhas na administração de antibióticos analisando sua possível influência na resistência bacteriana. Delineamento: realizada uma pesquisa bibliográfica das fontes do LILACS e Medline. Métodos: realizada revisão bibliográfica sistematizada com pesquisa de artigos de 1994 a 2005 na Internet usando-se os seguintes descritores juntamente com enfermagem: resistência bacteriana, controle de antibióticos, infecções hospitalares, administração de medicamentos, erros de medicações e eventos adversos. Foram selecionados 58 artigos que apresentaram correlação com a enfermagem e/ou eram básicos na fundamentação brasileira ou internacional. Resultados: Foram descritos aspectos gerais sobre a resistência bacteriana, antibióticos e custos incluindo estratégias para prevenção da resistência e classificações de erros utilizadas internacionalmente. Conclusões: Baseado nesse conhecimento são recomendadas intervenções para implementação do cuidado de enfermagem prático e seguro.

PALAVRAS-CHAVE: Erros de medicação; Enfermagem; Agentes antibacterianos: administração \& dosagem; Erros médicos: enfermagem; Composição de medicamentos: efeitos adversos; Resistência bacteriana a drogas; Infecção hospitalar: microbiologia.

ABSTRACT:The success of antibiotics treatment and development of bacterial resistance depend on many factors. The preparation and management of these factors are associated with nursing care. The aim of this paper is review literature about preparation, management and knowledge of intravenous antibiotics errors analyzing possibilities of influence of bacterial resistance prevention by nurses. Methods: a systematic review was done from LilLACS and Medline searching for the word nursing and bacterial resistance, antibiotics control, hospital infections, administration drugs, errors and adverse events. There were chose 58 papers about nursing and/or were basics for international and Brazilian studies. Results: It was described international classifications errors and consequences analyzing their possible influences on antibiotics effects. Based on these knowledge, interventions are recommended to implement safety practice and care.

KEY WORDS: Medication errors: nursing; Antibacterial agents: administration \& dosage; Medical errors: nursing; Drug compounding: adverse effects; Drug resistance, bacterial; Cross infection: microbiology.

RESUMEN: El suceso del tratamiento con antibióticos y el desarrollo de la resistencia de las bacterias son dependientes de muchos factores. La preparación y el manejo de ellos están asociadas a los cuidados de enfermería El objetivo de ese estudio es hacer una revisión sistemática sobre la preparación, administración y conocimientos con respecto a errores en la administración intravenosa de antibióticos y la posible influencia de la enfermería en la prevención de la resistencia bacteriana. Métodos: una revisión sistemática fue hecha en los datos de LILACS y Medline con las palabras enfermería y resistencia bacteriana, control de antibióticos, infecciones intra hospitalarias, administración de drogas, errores y eventos adversos. Fueron escogidos 56 publicaciones relacionadas a enfermería y/ó consideradas fundamentales en la literatura internacional y brasileña. Con base en esos conocimientos intervenciones fueron sugeridas para implementar cuidados más seguros a los enfermos

PALABRAS-CLAVE: Errores y drogas: enfermería; Agentes anti-bacterianos: administración y dosis; Errores médicos: enfermería; Componentes de las drogas: Efectos adversos; Resistencia bacteriana a las drogas; Infección cruzada: microbiología.

\footnotetext{
A presente revisão foi originada da Dissertação apresentada ao Programa de Pós-Graduação em Enfermagem da Escola de Enfermagem da UFRGS, como requisito para obtenção do título de mestre intitulada AVALIAÇÃO DA ADMINISTRAÇÃO DE CEFEPIMA A ADULTOS INTERNADOS EM UM HOSPITAL UNIVERSITÁRIO.

${ }^{1}$ Enfermeira. Mestre em Enfermagem. Professora da Escola de Enfermagem da Universidade Federal do Rio Grande do Sul. Porto Alegre/RS. E-mail: helocci@terra.com.br

2 Enfermeira, Doutora, Professora da Escola de Enfermagem da Universidade Federal do Rio Grande do Sul. Porto Alegre/RS. Email: lila@enf.ufrgs.br
} 


\section{INTRODUÇÃO}

A descoberta da penicilina em 1928 foi determinante na cura de milhares de pessoas. Entretanto, só se sabia que de alguma forma havia melhora no quadro clínico do paciente. Os reais efeitos da Penicilina e de outros antimicrobianos que vieram posteriormente foram descobertos mais tarde (como mecanismos de ação, e sobre o que eles agiam), pois os microrganismos eram ainda desconhecidos (LAPORT et al,1989) .

$O$ surgimento da resistência de microorganismos a estas drogas constituiu-se na evolução indesejada de um dos aspectos da terapêutica e do desenvolvimento tecnológico possibilitando a recuperação de problemas que no passado levavam à morte. Os pacientes sobrevivem por mais tempo no ambiente hospitalar mais expostos à flora bacteriana desenvolvendo de infecções que requerem tratamento. Por sua vez, materiais e superfícies contaminados com microorganismos modificados entram em contato com outros pacientes, infectando-os, criando, assim, uma cadeia interminável. $\mathrm{O}$ controle da resistência bacteriana depende de um raciocínio complexo envolvendo indicações de uso, política de utilização, forma de administração e questões financeiras ligadas aos hospitais e aos interesses da indústria de medicamentos.

O aumento dos dias de internação e os conseqüentes custos com terapêutica antimicrobiana, além das questões de cunho individual relacionadas à perda de salários e alterações psicológicas dos pacientes, por si só evidenciariam a importância da prevenção e controle das infecções hospitalares $(\mathrm{IH})$. As características multifatoriais que the são peculiares demandam medidas diversas, sendo que uma das mais importantes é o controle do uso dos antibióticos e conseqüentemente o controle da resistência bacteriana. A administração da dose, concentração e tempo de infusão corretos de um antibiótico, de forma geral, dependem, em grande parte da equipe de enfermagem (ASHP - AMERICAN SOCIETY OF HEALTH-SYSTEM PHARMACISTS, 2003) e da correta execução das orientações da farmacopéia. Concentrações maiores e infusões demasiado rápidas podem levar desde a reações locais, com inflamação, infecção e necessidade de tratamento, até a reações cutâneas gerando equívocos que levam à mudança desnecessária do antibiótico prescrito.

Visando retardar ou minimizar o desenvolvimento de um problema crescente que parece ser inevitável, diversos estudos e discussões têm sido realizados em torno do tema pelas associações de profissionais e por peritos sobre o assunto (LAPORT et al 1989; SHLAES et al., 1997; GERDING \& MARTONE, 2000; SINKOWITZCOCHRAN \& JARVIS, 2000; COIGNARD, B. et al. 2000).
O enfoque de pesquisadores conhecidos mundialmente direciona-se, predominantemente, à política do uso, à escolha e aos custos de antimicrobianos. Mesmo enfatizando que o desenvolvimento de resistência é multifatorial e sugerindo equipes para administração de antimicrobianos, aspectos relacionados ao cuidado de enfermagem são esquecidos (JARVIS, 1996; CARRICO et al., 2005; GAINES, 1995; MINOOEE \& RICKMAN, 2000).

No Brasil, as publicações de enfermagem que envolvem o tema são igualmente escassas. Artigos de revisões (PADILHA \& SECOLI, 2002; CASSIANI, 2000; SILVA \& CASSIANI, 2004) são mais freqüentes e os de pesquisa (MANENTI et al, 1998) sobre reações adversas de medicamentos não são específicos sobre antimicrobianos. Estudos sobre falhas de medicações são mais freqüentes na literatura internacional (LAPORT et al.,1989; HUNT \& RAPP, 1996; PADILHA, 1998) e sobre opiniões da enfermagem e sugestão de estratégias preventivas de erros de medicamentos aparecem em estudos brasileiros (BUENO, et al., 1998; CARVALHO et al, 1999). Artigos de pesquisa sobre antimicrobianos e enfermagem são raros (HOEFEL et al. 2004; HOEFEL \& LAUTERT L, 2006).

Assim, uma revisão teórica que possa embasar o ensino e a prática de enfermagem no que se refere a administração de antibióticos surge, portanto, como uma necessidade. Nesta perspectiva o objetivo do presente estudo foi identificar o que existe na literatura sobre administração de antibióticos pela enfermagem e a possível influência na resistência bacteriana.

\section{MATERIAIS E MÉTODOS}

Foi realizada uma pesquisa bibliográfica, usando-se os seguintes descritores juntamente com enfermagem: resistência bacteriana, controle de antibióticos, infecções hospitalares, administração de medicamentos, erros de medicações e eventos adversos através da utilização das bases de dados LILACS e Medline do período de 1995 a 2005. Foi realizada também pesquisa direta através da Internet. Artigos com datas anteriores à 1995 foram utilizados quando recomendados como padrão atual em associações reconhecidas.

Foram selecionados 56 artigos que apresentaram correlação entre esses termos, sempre que associados à administração de antibióticos, assim como aqueles que auxiliaram no desenvolvimento do raciocínio lógico utilizado para análise.

Os temas constantes nos artigos revisados foram organizados em duas categorias. A primeira refere-se aos aspectos gerais sobre resistência bacteriana e antibioticoterapia, onde são abordados questões relativas aos custos das infecções hospitalares e antibióticos; o desenvolvimento da 
resistência bacteriana e estratégias para sua prevenção, as quais subsidiam os dados apresentados na categoria administração de medicamentos e falhas.

\section{RESULTADOS E DISCUSSÃO}

\section{Aspectos gerais sobre resistência bacteriana e antibioticoterapia}

\section{Custos, infecções hospitalares e antibióticos}

As infecções hospitalares ocasionam custos consideráveis aos sistemas de saúde de todo o mundo. Os estudos do americano WENZEL (1995) sobre custos são clássicos e bem aceitos, tendo influenciado autores de países tão distintos entre si como Espanha (PEÑA et al, 1996) e Noruega (ANDERSEN, 1998).

Em um estudo realizado em hospitais de Belo Horizonte (REZENDE et al, 1998), a infecção cirúrgica foi identificada como o segundo sítio de maior freqüência de infecções hospitalares e pontuaram diversas questões, incluindo evitar a antibioticoprofilaxia indiscrimanada para redução da prevalência de infecções e custos associados.

CARDO \& SOULE (1999), realizando uma análise do tema, evidenciam a questão dos gastos com drogas específicas utilizadas erroneamente. Nesta mesma linha, está o trabalho de HEINECK et al. (1999) no Hospital de Clínicas de Porto AlegreRS. Os autores constataram que a antibioticoprofilaxia correta no que se refere a doses e horário de administração de algumas cirurgias não era seguida pelos cirurgiões, levando ao aumento de custos e indução na resistência bacteriana. O aumento da resistência fatalmente leva ao aumento dos custos pelo uso de drogas mais potentes e mais caras.

Controladores brasileiros de infecção hospitalar, ponderando sobre a situação do país relatam a mobilização de hospitais universitários para prevenir a resistência bacteriana como descreveram PANUTTI \& GRINBAUM (1995) através da restrição de cefalosporinas, aztreonam, imipenem, quinolonas e vancomicina. Os custos financeiros associados a esses e outros antibióticos que os controladores de infecção tentam preservar são grandes. A preservação destas drogas na prevenção da resistência representa uma estratégia para a situação alarmante de um país em que o sistema de saúde é precário e as verbas destinadas à saúde pública são insuficientes. Com o planejamento para prevenir os erros e abusos de antibióticos, WEY (1995) relata que $17 \%$ das solicitações de antimicrobianos, segundo um estudo realizado no Hospital São Paulo foi negado pelo controle de infecção hospitalar, significando uma economia de $\cup \$ 300,000$ por ano. A influência da prática de enfermagem com a omissão de doses ou outros erros pode levar ao insucesso terapêutico que conseqüentemente trará mais gastos. O papel da administração de medicamentos pela enfermagem e custos relacionados é omisso na literatura.

\section{Desenvolvimento da resistência bacteriana}

As diferentes características na composição, farmacodinâmica e farmacocinética das diferentes drogas determinam o modo de administração, diluição e tempo necessário para a efetividade e segurança (GAINES, 1995; MINOOEE \& RICKMAN, 2000). Para alguns tipos de antibióticos a influência do tempo de infusão e intervalos de administração pode ser expressiva sobre a curva farmacodinâmica. Entretanto, raras são as publicações que analisam esses aspectos que dependem, na maioria das vezes da enfermagem (HOEFEL et al. 2004; HOEFEL \& LAUTERT L, 2006).

O desenvolvimento da resistência bacteriana é, até o presente momento, considerada inexorável. $\mathrm{O}$ uso de antimicrobianos com espectro maior do que necessário, o esquema posológico inadequado e o tempo prolongado de antibioticoterapia são fatores que facilitam a seleção de cepas resistentes (MANRIQUE \& GALVÃO, 1996).

O uso de antibióticos de amplo espectro estendeu-se com a quimioterapia oncológica, a expansão dos transplantes e terapêuticas com maior poder de alteração da resposta imune elevaram o número de pacientes com predisposição a infecções por microrganismos resistentes. Sob a pressão seletiva dos antibióticos, as bactérias desenvolveram defesas que as tornaram extremamente difíceis de combater.

Elas podem desenvolver mutações cromossômicas, expressar um gene latente com resistência cromossomal ou adquirir um novo material genético através de troca direta de DNA (por conjugação), por um bacteriófago (transdução), através de plasmídeo de DNA extra cromossomal (conjugação) ou pela aquisição de DNA por transformação. A informação codificada neste material genético possibilita a bactéria desenvolver resistência através de três maiores mecanismos: produção de uma enzima que irá inativar ou destruir o antibiótico; alteração do local onde o antibiótico iria se ligar para impedir a ação da droga; ou prevenção do acesso do antibiótico ao local de ligação (SHLAES et al., 1997).

As definições de resistência bacteriana, com finalidade epidemiológica, variam de acordo com a instituição hospitalar. A definição inicial de bactérias resistentes elaborada pelo Centers for Disease Control and Prevention (1996) estava ligada aos microorganismos gram negativos resistentes aos aminoglicosídeos, Staphylococcus aureus resistentes à meticilina, Pneumococco resistente a penicilina e Haemophillus resistente à ampicilina. No Brasil, o Staphylococcus aureus resistente à oxacilina, era o 
foco de atenção à resistência como no estudo de MARQUES et al. (1989) pois na época a meticilina não era utilizada. Atualmente, a classificação é de acordo com a resistência nas instituições e conforme as melhores opções terapêuticas da política institucional de controle dos antibióticos (ANDREMONT A, 2001).

$\mathrm{Na}$ análise dos resultados de dois estudos multicêntricos na América Latina publicados por SADER (2000), foi detectada no Brasil uma resistência muito maior de cepas produtoras de betalactamases de espectro estendido, em relação aos estudos americanos e europeus. Outro problema de resistência bacteriana no Brasil, de acordo com o estudo, foi relacionado às enterobacterias com resistência à terceira geração de cefalosporinas devido à produção de cefalosporinases (indutoras de beta-lactamases) mediadas por cromossomas. $O$ gênero mais importante produtor deste tipo de betalactamases (com 20\% de isolados no sangue) foi Citrobacter sp., Enterobacter sp. e Serratia sp. As enterobactérias representaram $14,4 \%$ sendo que o Enterobacter cloacae foi a espécie mais isolada, apresentando alta resistência aos beta-lactâmicos astreonam e piperacilina-tazobactam.

Os Staphylococcus aureus representam os microorganismos de maior incidência nas infecções hospitalares. A redução da sensibilidade à vancomicina está descrita pelo U. S. Department of Health Care Services (UNITED STATES OF AMERICA, 1997) e representa uma grande preocupação por se tratar de uma das últimas opções terapêuticas a este microorganismo. A ocorrência de enterococccus resistentes à vancomicina é mais freqüente e é alvo de igual ou maior preocupação. A possibilidade da transferência de resistência dos enterococos aos estafilococos através do gene Van A já era motivo de preocupação quando o Hospital Infection Control Practices Advisory Committee (1995) do Centro de Controle de Doenças Americano, desenvolveu recomendações gerais para prevenir a disseminação de enterococos resistentes. Mais recentemente os enterococos mereceram um artigo de revisão específico elaborado por CETINKAYA et al. (2000), no qual foram descritas as diferentes formas de aquisição e disseminação de resistência desses microorganismos.

As bactérias produtoras de enzimas betalactamases de espectro estendido, popularmente chamadas de ESBL (Extended Spectrum Beta Lactamasis), representam igualmente uma grande preocupação referente à resistência bacteriana.

O aparecimento da multirresistência aos antibióticos beta-lactâmicos ocorre freqüentemente durante a terapia de infecções por gram negativos (FERNANDES, 2006; BURGERT \& BURKE, 1994; BISSON et al., 2002). A indução da produção de beta-lactamases pode ser temporária e é associada a presença da enzima, a qual é freqüentemente produzida por enterobactérias e conferem resistência aos monobactâmicos e beta-lactâmicos. Elas são expressas por genes existentes em plasmídeos que podem ser transferidos a outras bactérias. Microrganismos que possuem esta característica cromossômica incluem além de Enterobacter sp, Citrobacter freundii, Providencia sp e algumas cepas de Proteus sp. O uso de cefalosporinas de terceira geração, assim como mobactâmicos e penicilinas de espectro estendido têm sido associados com essa classe de multirresistência. As dificuldades de tratamento das cepas com este tipo de resistência devem-se a diversos fatores. Um deles é referente ao fato de que elas carregam os plasmídeos que conferem resistência a diversos antibióticos.

A colonização e a infecção por bactérias multirresistentes é o resultado de diversos fatores. $\mathrm{Na}$ posição oficial da Sociedade de Epidemiologistas da América (Society for Healthcare Epidemiology of América-SHEA) foi ponderado que a gravidade da doença, antibióticos utilizados de forma inadequada por seleção, dosagem e duração do tratamento, assim como a não adesão às medidas preventivas para bloqueio da transmissão de microorganismos, são fatores reconhecidos como determinantes do aumento da resistência bacteriana (SHLAES, 1997). Além disso, ocorrendo resistência ao antibiótico escolhido há necessidade de uso de outras alternativas que com freqüência são associados a maior toxicidade. GAINES (1995) em editorial sobre a resistência de microorganismos alerta para o fato de que nenhuma estratégia será adequada a menos que seja vista por toda a equipe e sistema de saúde como um problema vital. A publicação da SHEA faz referência clara à preocupação com a participação dos enfermeiros para auxílio na solução dos problemas, mas em nenhum momento indica pontos específicos relacionados à atuação da enfermagem que poderiam ter influência no controle de antimicrobianos e prevenção da resistência bacteriana.Os dados sobre a resistência bacteriana e a administração pela enfermagem são inexistentes.

\section{Estratégias para prevenção da resistência bacteriana}

A SHEA, em conjunto com a Infectious Diseases Society of América elaborou um consenso (SHLAES,1997) mais conhecido como uma "posição" da SHEA, para medidas preventivas de resistência bacteriana em hospitais. Os especialistas dizem que algumas bactérias que adquirem mutações em genes responsáveis por funções vitais, como o transporte de pequenas moléculas, apesar de resistentes a alguns antibióticos, podem ser menos resistentes em modelos animais. Entretanto, tais bactérias podem ser responsáveis pela falha do tratamento, porque não foram efetivamente tratadas pelo antibiótico, nem foram eliminadas pelas defesas diminuídas do hospedeiro. 
Com base nos estudos existentes, o consenso da SHEA é de que mudanças no uso dos antibióticos são acompanhadas de mudanças na prevalência de bactérias resistentes. Outras considerações referem-se ao fato de que, durante surtos de multi resistentes, os portadores dessas bactérias fizeram uso prévio de antibióticos, ao ponto de que áreas com maior uso de antimicrobianos têm maior probabilidade de possuir microorganismos resistentes e a que quanto maior a duração da exposição do paciente a ciclos de antibióticos, maior a probabilidade do desenvolvimento da resistência. A respeito do uso dos antibióticos e desenvolvimento da resistência bacteriana a SHEA reconhece que muitas questões ainda permanecem sem resposta em função das definições variarem de acordo com diferentes autores, assim como a constatada existência de fatores de confusão nas pesquisas e outros problemas metodológicos devido à dificuldade de controlar algumas variáveis (EVEILLARD et al., 2002; YU et al. 2002).

A escolha, uso, administração, cuidado na dosagem a fim de evitar terapêuticas e doses inadequadas que levam à resistência bacteriana é a responsabilidade que cabe à equipe de saúde como um todo.

A interferência das ações da enfermagem nas curvas farmacodinâmicas pode ser deduzida dos itens apontados no consenso da SHEA. Entretanto o texto refere-se basicamente ao papel dos médicos e da farmácia hospitalar. A dispensação por doses unitárias já preparadas e diluídas conforme a necessidade, cabendo à enfermagem apenas sua administração é uma alternativa prática.

\section{Administração de medicamentos e falhas}

A Sociedade Americana de Sistemas Farmacêuticos de Saúde (ASHP - AMERICAN SOCIETY OF HEALTH-SYSTEM PHARMACISTS, 2003a) é uma associação que subsidia a prática de farmacêuticos nos sistemas de saúde e nos aspectos relacionados ao uso de medicações e saúde pública incluindo orientações para todos os profissionais envolvidos com medicamentos. A ASHP (1980) em sua normalização, ainda vigente em 2005 , referente à distribuição e controle de drogas sublinha a necessária atenção aos riscos das administrações de drogas incompatíveis relacionadas aos tipos de sistemas de administração. A responsabilidade de quem administra o medicamento, de acompanhar o paciente até o final da infusão e o treinamento especifico para administrar medicamentos é um dos aspectos citados. As normas devem ser elaboradas pela própria instituição e escritas com detalhamento.

A ASHP (1995) define reação adversa como qualquer resposta indesejada, desconhecida, inesperada ou excessiva a uma droga que a) requer suspensão da droga (terapêutica ou diagnóstica); b) requer mudança na terapêutica; c) requer modificação da dose (exceto para ajustes de doses menores); d) necessita internação hospitalar; e) prolonga a estadia em instituição de saúde; f) necessita tratamento; g) complica significantemente 0 diagnóstico; h) afeta negativamente o prognóstico; i) resulta em prejuízo temporário ou permanente, incapacitação ou morte.

As reações adversas aos medicamentos podem ocorrer por diferentes razões. Uma delas pode estar relacionada à droga em si. Pessoas diferentes podem ter reações diferentes a um mesmo medicamento. Os aspectos relacionados a farmacocinética clínica com determinação do regime da dosagem de drogas para pacientes específicos para maximizar os efeitos farmacoterapeuticos e minimizar os efeitos tóxicos devem ser lembrados. A farmacocinética clínica requer entendimento de absorção, distribuição, metabolismo e excreção característicos de drogas específicas em populações específicas.

Além destes aspectos que são inerentes às drogas e/ou aos pacientes, as reações adversas podem ocorrer em decorrência de eventos relacionados à erros ou enganos.

Apesar das definições de alguns autores serem similares (BUENO et al., 1998; BECHTEL et al., 1993), estes adotam diferentes abrangências de eventos adversos e erros, relacionados a drogas. As definições adotadas pela ASHP (1993) são oriundas de diversos estudos, sendo bastante amplas abarcando a seguinte classificação:

a) Erro de prescrição - seleção incorreta da droga (baseada em indicações, contra - indicações, alergias conhecidas, terapia existente e outros fatores), dose, forma de dosagem, quantidade, via, concentração, velocidade de administração, ou instruções para uso de um produto ordenado ou autorizado por um médico (ou outro com autoridade de prescrição); prescrição ilegível ou ordens prescritas que permitem erros que prejudicam o paciente;

b) Erro de omissão - falha na administração de uma dose prescrita a um paciente antes de uma próxima, se existir;

c) Erro de tempo - administração de medicamento fora de um intervalo pré-definido de tempo do esquema de administração (este intervalo pode ser estabelecido por cada instituição);

d) Erro de medicamento não autorizado administração de medicamento não prescrito;

e) Erro de dosagem imprópria - administração ao paciente de uma dosagem que é maior ou menor que a quantidade prescrita ou administração de dose duplicada. Isto é, uma ou mais doses administradas além daquelas prescritas;

f) Erro no preparo do medicamento - droga formulada ou manipulada incorretamente antes da administração;

g) Erro de técnica de administração inadequada procedimento inapropriado ou técnica de administração imprópria; 
h) Erro de deterioração da droga - administração de medicamento com data de validade vencida ou cuja integridade física ou química ficou comprometida;

i) Erro de monitoramento - falha na revisão de um esquema prescrito para detecção de problemas ou falha no uso de dados laboratoriais ou clínicos para identificar a resposta adequada de um paciente a terapia;

j) Erro de adesão - comportamento inadequado do paciente no que se refere à aderência a um esquema de medicamentos prescrito;

k) Outros erros - qualquer outro erro que não os citados nas categorias listadas anteriormente.

Como conseqüências do erro, a ASPH classifica os erros em diferentes níveis:

nível zero- não ocorreu erro (erros potenciais são classificados neste nível);

nível 1 - erro que não resultou em dano ao paciente;

nível 2 - erro que resultou na necessidade de monitoração mas sem alterações nos sinais vitais ou dano ao paciente;

nível 3 - erro resultou na necessidade do aumento da monitoração do paciente com alteração dos sinais vitais mas sem maiores danos ao paciente, ou qualquer erro que resultou na necessidade de aumentar monitoramento laboratorial;

nível 4 - Erro resultou na necessidade de tratamento com outra droga ou aumento na estadia ou que afetou a participação do paciente em uma pesquisa com medicamento;

permanente;

nível 5 - erro que resultou em dano

nível 6 - erro resultou em morte.

Todavia, verifica-se que erros na administração de medicamentos, eventualmente acontecem (ASHP - AMERICAN SOCIETY OF HEALTH-SYSTEM PHARMACISTS,1998). Um exemplo é a investigação de Hoefel et al. (2004) sobre o preparo e administração de Vancomicina pela enfermagem, quando foram identificadas $57 \%$ de administrações de doses incompletas, decorrentes de resíduos que permaneciam nos equipos de soro após a administração.

\section{Erros de doses}

Doses maiores e volumes maiores de diluentes podem igualmente influenciar a forma de preparo e administração pelo pessoal de enfermagem. A vancomicina, por exemplo, em dose de 500 mg deve ser diluída em $100 \mathrm{ml}$ e correr em 60 minutos. Entretanto, se for diluída em menor volume, expõe o paciente à possibilidade de reações adversas, o que poderia levar à troca de terapêutica. Adicionalmente, se houver resíduo no equipo de infusão, a perda é proporcionalmente maior quanto mais concentrada a droga. Erros decorrentes de resíduos de antibióticoos no equipo após administração foram identificados em dois estudos citados, um de HOEFEL et al. (2004) e outro de HOEFEL \& LAUTERT (2006). A questão de resíduos de outras medicações tem sido estudada por outros autores.

\section{Erros de prescrição}

Situações de sobreposição de tarefas como pacientes com prescrição de mais de uma medicação para o mesmo horário e medicamentos prescritos para diferentes pacientes com aprazamentos para o mesmo horário foram identificados por autores (HOEFEL, 2006; CARVALHO \& CASSIANI, 2002) que ouviram depoimentos sobre "medicamentos no mesmo horário" e "muitos pacientes ao mesmo tempo". Isso sugere a possibilidade de que os profissionais desejem adiantar 0 horário de administração da medicação ou a velocidade com que a medicação é administrada. A antecipação ou postergação do horário e de velocidade de gotejo aumentado ou diminuído pode apresentar diferentes conseqüências para o paciente conforme o tipo de antibiótico, a sua farmacologia e características individuais como o clearence renal do paciente, por exemplo.

Bombas de infusão para controle do fluxo são alternativas que beneficiam a acurácia do fluxo necessitam de medidas coadjuvantes, pois esse tipo de sistema para controle é falível (PEÑA et al., 1996) e os erros são freqüentes.

\section{Concentração e níveis de absorção de antibióticos}

A farmacocinética (LABARCA, 2002), avalia os processos que determinam a concentração de um antimicrobiano em relação ao tempo em nível sérico e nos tecidos corporais. Estas concentrações são alcançadas através de três processos: absorção, distribuição e eliminação do fármaco. Na curva de concentração sérica de um antibiótico, após a administração, se observa uma fase em que a concentração aumenta rapidamente até alcançar o pico de concentração. A seguir ocorre a distribuição nos tecidos e a redução do nível plasmático é acelerada. A fase final de redução lenta da concentração é correspondente à eliminação do fármaco do organismo. A área localizada sob a curva é utilizada para avaliar o efeito dos diferentes tipos de antibióticos, de acordo com sua forma de ação. O efeito de alguns antibióticos é mais dependente do tempo enquanto outros da concentração.

A área sob a curva aumenta proporcionalmente as doses utilizadas, traduzindo uma linearidade na farmacocinética da droga. A capacidade de ação das cefalosporinas é dependente do tempo em que a área sob a curva (LABARCA, 2002; MARÍN \& GUDIOL, 2003) fica acima da concentração inibitória mínima (Minimum Inibitory Concentration - MIC) para eliminar um 
microorganismo específico, que deve ser de 40 a $60 \%$ do tempo de intervalo entre duas doses. A medida da área sob a curva depende da dose administrada, do tempo de infusão e da eliminação renal. Em patologias renais com clearances da creatinina menores do que $30 \mathrm{ml} / \mathrm{min}$ recomenda - se reduzir a dose já que a eliminação será mais lenta (CÁRDENAS et al., 2001; GARRELTS \& WAGNER, 1999).

A distribuição nos tecidos não é incrementada mesmo na infusão de concentrações maiores ou permanência de concentrações altas a nível sérico por mais tempo, havendo, portanto um limite de atuação. Drogas dependentes de concentração, não apresentam esse limite, aumentando a potência com a concentração sérica.

$O$ estudo dos modelos auxilia nas orientações sobre a padronização de períodos de infusão e intervalos entre doses. Se houver aumento dos intervalos de administração da droga, haverá alteração da área localizada sob a curva, acima do MIC, podendo haver alteração no efeito do medicamento.

\section{Enfermagem e a administração de antibióticos}

A enfermagem deve assegurar tempos de administração corretos das drogas e se em "bolus" ou não a fim de ser coadjuvante no sucesso terapêutico. Esses aspectos são referentes à eficácia terapêutica com manutenção dos níveis séricos e teciduais necessários à morte bacteriana. Infusões lentas restringem os pacientes a ficarem ligados aos equipos de infusão. Além disso, a lentidão demasiada para infusão de alguns antibióticos podem impedir que as concentrações sérica e tecidual sejam mantidas.

A administração em "bolus" em 3 minutos é aceita em alguns casos para as mesmas drogas com períodos de infusão indicados de 20 e 30 minutos, em pacientes com restrição de líquidos (TRISSEL, 2001). Nesses casos, dificilmente uma dose mais concentrada infundida em pequeno período de tempo levará a um evento adverso. Entretanto, drogas como a vancomicina, por exemplo, que devem ser administradas em 60 minutos e sua concentração após diluição deve ser de $5 \mathrm{mg} / \mathrm{ml}$ pois administrações muito rápidas ou concentrações mais altas levam a reações indesejadas, colocando o paciente em risco (POLK, 1993).

Os autores da atual revisão recomendam a adição de $20 \mathrm{ml}$ de soro fisiológico ao final da dose intravenosa na bolsa do medicamento, deixando o restante da dose fluir. Não foi encontrada recomendação alternativa na literatura básica sobre administração pela enfermagem. A utilização de bombas de infusão auxilia no controle de fluxo da infusão, mas apresentam falhas (ROSENTHAL, 2004; $\mathrm{HUSCH}$ et al., 2005) nesse controle e necessitam igualmente, de que o equipo seja preenchido para que toda a dose seja administrada.

\section{CONSIDERAÇÕES FINAIS}

A administração de antibióticos requer controle rigoroso da enfermagem dos horários, diluições e intervalos entre doses para que o efeito entre o pico máximo de ação e o nível mínimo requerido para morte bacteriana seja o esperado para terapêutica eficaz evitando seleção de organismos resistentes.

Não se pode afirmar, que administrações de doses inferiores às prescritas, por erros de preparo e administração determinam atraso da cura ou mesmo ineficácia do tratamento. Entretanto, esses riscos são iminentes e o conhecimento sobre a administração é determinante para o êxito da terapêutica.

Falhas repetidas de doses menores ou intervalos inadequados em um mesmo paciente fatalmente levarão ao insucesso terapêutico. Administrações de doses completas são de responsabilidade de todos os envolvidos no processo, desde o preparo até a infusão. Utilizar equipamentos que evitem doses incompletas pode ser uma das alternativas para minimizar o problema (FORD et al., 2003).

Estudos aprofundados que possam identificar as formas efetivas de prevenção de erros, principalmente em áreas críticas, são fundamentais. Em um estudo de PEREIRA et al. (2000), enfermeiras de áreas de risco para infecções hospitalares e resistência bacteriana deixaram de citar administração de antimicrobianos, por exemplo, quanto questionadas sobre desafios no controle de infecções na área. À luz dos estudos existentes não se pode afirmar que erros na administração de antibióticos pela enfermagem influenciam a flora bacteriana.

No entanto, controlar os passos do processo de preparo e administração é o caminho lógico para a prevenção da resistência bacteriana. Isso porque as prescrições dos antibióticos, intervalos de tempo entre doses e determinação das concentrações são oriundos dos estudos farmacológicos padronizados que possuem eficácia terapêutica comprovada determinando a morte bacteriana.

\section{REFERÊNCIAS BIBLIOGRÁFICAS}

ANDERSEN, B.M. Economic consequences of hospital infections in a 1000 bed universitary hospital in Norway. Infection Control and Hospital Epidemiology. v.19, n.10, p.805-807, 1998.

ANDREMONT, A. The future control of bacterial resistance to antimicrobial agents. American Journal of Infection Control. v.29, n.4, p.256-258, 2001.

ASHP - AMERICAN SOCIETY OF HEALTH-SYSTEM PHARMACISTS. ASHP guidelines on adverse drug reaction monitoring and reporting. American Journal of Health-System Pharmacy. v.52, n.4, p.417-9, 1995. 
ASHP policy positions: 1982-2003.

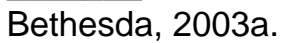

ASHP statement on the pharmacist's role in clinical pharmacokinetic monitoring. In: ASHP. Medication therapy and patient care: specific practice areas-statements. American Journal of HealthSystem Pharmacy. v.55, n. 16, p.1766- 7, 1998.

ASHP technical assistance bulletin on hospital drug distribution and control. In:

Drug distribution and control: distribution-technical assistance bulletins. American Journal of HealthSystem Pharmacy. [online] 1980. Disponível em: http://www.ajhp.org/cgi/external ref?access num $=74$ 05941\&displayid=147468\&link type=INFOTRIEVE

[Acesso em: 5 jul. 2004]

Pharmacy - nursing shared vision for safe medication use in hospitals: executive session summary. American Journal of Health-System Pharmacy. v.60, n.10, p.1046- 1051, 2003.

ASHP guidelines on preventing medication errors in hospitals. American Journal of HealthSystem Pharmacy. v.30, n.2, p.305-314, 1993.

BECHTEL, G. A et al. A continuous quality improvement approach to medication administration. Journal Nursing Care Quality. v.7, n.3, p.28-34, 1993.

BISSON, G. et al. Extended - spectrum $\beta$ - lactamase - producing Escherichia coli and Klebsiela species: risk factors for colonization and impact of antimicrobial formulary interventions on colonization prevalence. Infection Control and Hospital Epidemiology. v.23, n.5, p.254-260, 2002.

BUENO, E.et al. Erros na administração de medicamentos: fatores de risco e medidas empregadas. Revista Baiana de Enfermagem. v.11, n.1, p.101-119, 1998.

BURGERT, S. J. \& BURKE, J. P. Antibiotic resistance: will infection control meet the challenge? American Journal of Infection Control. v.22, n.4, p.193-194, 1994.

CARDENAS, E. et al. Farmacologia de cefepima. Emergências. v.13, n.7, p.S57-S62, 2001.

CARDO, D. \& SOULE, B. Hospital infection and prevention and control: a global perspective. American Journal of Infection Control. v.27, n.3, p.233-235, 1999.

CARRICO, R. et al. Antimicrobial resistance: a primer for infusion specialists. Journal of Infusion Nursing. v.28, n.3, p. 18, 2005.

CARVALHO, V.T. et al. Erros mais comuns e fatores de risco na administração medicamentos em unidades básicas de saúde. Revista LatinoAmericana de Enfermagem. v.7, n.5, p.67-75, 1999.

CARVALHO, V. T. \& CASSIANI, S. H. B. Erros na medicação e conseqüências para profissionais de enfermagem e clientes: um estudo exploratório. Revista Latino-Americana de Enfermagem. v.10, n.4, p.523-9, 2002.

CASSIANI, S. H. B. Erros na medicação: estratégias de prevenção. Revista Brasileira de Enfermagem. v.53, n.3, p. 424-430, 2000.
CENTERS FOR DISEASE CONTROL AND PREVENTION. Guideline for isolation precautions in hospitals. American Journal of Infection Control. v.24, n.1, p.24-52, 1996.

CETINKAYA, $\mathrm{Y}$ et al. Vancomycin-resistant enterococci. Clinical microbiology reviews. v.13, n.4, p.686-707, 2000.

COIGNARD, B. et al. Reality check: how should we control antimicrobial use? Current practices and controversies. Infection Control Hospital Epidemiology. v.21, n.121, p.792-795, 2000.

EVEILLARD, M.; SCHMIT, J. L.; EB F. Antimicrobial use prior to the acquisicion of multiresistant bacteria. Infection Control Hospital Epidemiology. v.23, n.3, p.155-158, 2002.

FERNANDES, A. T. Betalatamases de espectro estendido. [online] 2001. Disponível em: http://www.ccih.med.br/icaac14a.html. [Acesso em 5 nov. 2006].

FORD N A, DROTT H D, CIEPLINSKI ROBERTSON. Administrations of IV medications via soluset. Pediatric Nursing. v.29, n.4, p.283-86, 2003.

GAINES, R. Antibiotic in ICUs: a multifaceted problem requiring a multifaceted solution. Infection Control Hospital Epidemiology. v. 16, n. 6, p. 328-330, 1995.

GARRELTS, J. C.; WAGNER, D. J. The pharmacokinetics, safety and tolerance of cefepime administered as an intravenous bolus or as a rapid infusion. The Annals of Pharmacotherapy. v.33, n.12, p.1258-1276, 1999.

GERDING, D. N.; MARTONE, W. J. SHEA conference on antimicrobial resistance. Infection Control and Hospital Epidemiology. v.21, n.5, p.347351, 2000.

HEINECK, I. et al. Prescribing practices for antibiotic profilaxis for 3 commonly performed surgeries in a teaching hospital in Brazil. American Journal of Infection Control. v.27, n.3, p.296-300, 999.

HOEFEL H \& LAUTERT L. Errors committed by nursing technicians and assistants in administrating antibiotics. American Journal of Infection Control. v.34, p 437-42, 2006.

HOEFEL, $H$. et al. Vancomycin administration in an universitary hospital at general surgical units inpatients. OBJN. 2004; [On line]. Disponível em: http://www.uff.br/nepae/objn301hoefeletal.htm.

[Acesso em 15 de nov. 2006]

HOSPITAL INFECTION CONTROL PRACTICES ADVISORY COMMITTEE . Recommendations for preventing the spread of vancomycin resistance. Infection Control and Hospital Epidemiology. v.16, n.2, p.105-113, 1995.

HUNT, M. L.\& RAPP, RP. Intravenous medications errors. Journal of Intravenous Nursing. v.19, p.S9S15, 1996.

HUSCH M et al. Insights from the Sharp end of intravenous medication errors: implications for infusion pump technology. Qual Saf Health Care. v.14, n.2, p.80-86, 2005. 
JARVIS, R. Preventing the emergence of multidrugresistant microorganisms through antimicrobial use controls: the complexity of the problem. Infection Control Hospital Epidemiology. v.17, n.8, p.490-495, 1996.

LABARCA, J. L. Nuevos conceptos en farmacodinamia, debemos repensar cómo administramos antimicrobianos? Revista Chilena de Infectologia. v. 19, supl. 1, p. S33-S37, 2002.

LAPORT, J. R.; TOGNONI, J.; ROZENFELD, S. Epidemiologia do medicamento: princípios gerais. 2 . ed. Rio de Janeiro: HUCITEC-ABRASCO, 1989.

MANENTI, S. et al. Ocorrências adversas com medicação em unidade de terapia intensiva: análise da administração de soluções hidroeletrolíticas e antibióticos. Revista da Escola de Enfermagem da USP. v.32, n.4, p.369-376, 1998.

MANRIQUE, E. I. \& GALVÃO, L. L. Racionalização e controle de antimicrobianos. In: RODRIGUES E. et al. Infecções hospitalares: prevenção e controle. São Paulo: Sarvier, 1996.

MARÍN, M. \& GUDIOL, F. Antibióticos betalactámicos. Enfermedades Infecciosas Microbiología Clínica. v.21, n.1, p. 42-45, 2003.

MARQUES, A.; PETRILLO, V. F.; HOEFEL, H. H. K. Methicillin resistant $S$. aureus in general hospital in Brazil. The Journal of Hospital Infection. v.14, n.4, p.380-381, 1989.

MINOOEE, A. \& RICKMAN, L. S. Expanding the role of the infection control professional in the cost effective use of antibiotics. American Journal of Infection Control. v.28, n.1, p.57-65, 2000.

PADILHA, K.G. Ocorrências iatrogênicas na prática de enfermagem em Unidade de Terapia Intensiva. 1998. 103 f. Tese (Livre -Docência) - Escola de Enfermagem, Universidade de São Paulo, São Paulo, 1998.

PADILHA, K.G. \& SECOLI, S.R. Erros na administração de medicamentos. Prática Hospitalar. v.4, n.19, p.24-29, 2002.

PANUTTI, C. \& GRINBAUM, R. An overview of nosocomial infection control in Brazil. Infection Control and Hospital Epidemiology. v.16, n.3, p.170174, 1995.

PEÑA, C. et al. Estimación del coste atribuible a la infección nosocomial: prolongación de la estancia hospitalaria y calculo de costes alternativos. Medicina Clínica. v.106, n.12, p.441-444, 1996.

PEREIRA, M. S et al. Controle de Infecção Hospitalar em Unidade de terapia Intensiva: desafios e perspectivas. Revista Eletrônica de Enfermagem. [on line] 2000. Disponível em: http://www.fen.ufg.br/revista/revista2 1/01.htm

[Acesso em 23 dez 2006].

POLK, R.E. Vancomycin Skin Tests and Prediction of "Red Man Syndrome"in Healthy Volunteers. Antimicrob Agents Chemother. v.37, n.10, p.2139-43, 1993.

REZENDE, E. M. et al. Prevalence of nosocomial infections in general hospitals in Belo Horizonte.
Infection Control and Hospital Epidemiology. v.19, n.11, p.872-876, 1998.

ROSENTHAL K. Smart pumps help crack the safety code. Nursing Management. v.35, n.5, p.49-51, 2004. SADER, H. Antimicrobial resistance in Brazil: comparison of results from two multicenter studies. The Brazilian Journal of Infectious Diseases. v.4, n.2, p.91-99, 2000.

SHLAES, D. et al. SHEA position paper: Society for Healthcare Epidemiology of America and Infectious Diseases Society of America Joint Committee on the prevention of antimicrobial resistance: guidelines for the prevention of antimicrobial resistance in hospitals. Infection Control Hospital Epidemiology. v.18, n.4, p.875-891, 1997.

SILVA, A. E. B. C. \& CASSIANI, S. H. B. Administração de medicamentos: uma visão sistêmica para o desenvolvimento de medidas preventivas dos erros na medicação. Revista Eletrônica de Enfermagem. [on line] 2004. Disponível em:

http://www.fen.ufg.br/revista/revista6 2/administra.ht ml [Acesso em 23 dez 2006].

SINKOWITZ-COCHRAN, R.; JARVIS, W. Evaluation of a satellite education program on the prevention and control of antimicrobial resistance. American Journal of Infection Control. v.28, p.267-282, 2000.

TRISSEL, L. A. Handbook on injectable drugs. 11. ed. Bethesda: American Society of Hospital Pharmacists, 2001.

UNITED STATES OF AMERICA. Department of Health and Human Services. Update: Staphylococcus aureus with reduced susceptibility to vancomycin United States, 1997. Morbidity and Mortality Weekly Report. v.46, n.35, p.813-815, 1997.

WENZEL, R. P. The economics of nosocomial infections. Journal of Hospital Infections. v.31, n.2, p.79-87, 1995.

WEY, S. Infection control in a country with annual inflation of $3,600 \%$. Infection Control and Hospital Epidemiology. v. 16, n.3, p.175-178, 1995.

YU, W. L. et al. Cefepime MIC as a predictor of the extended-spectrum beta-lactamase type in Klebsiela pneumoniae, Taiwan. Emerging Infectious diseases. v.8, n.5, p.522-524, 2002.

Artigo recebido em 16.11.06

Aprovado para publicação em 29.12.2006 